EPiC Series in Language and Linguistics
Volume 2, 2017, Pages 135-142
Professional and Academic Discourse:
an Interdisciplinary Perspective

\title{
The role of English as a Lingua Franca in European projects: The case of the RSGAE project
}

\author{
Andrea Olivares-Beltrán and Teresa Morell \\ Universidad de Alicante, Alicante, Spain \\ alob1@alu.ua.es,mt.morell@ua.es
}

\begin{abstract}
English is undoubtedly the Lingua Franca (ELF) in Europe, as it is used for academic and professional communication. However, it is also used to foster other European languages for specific purposes in different countries and contexts. In this paper we will refer to the role of ELF as a tool to promote multilingualism. In order to provide a pragmatic example, we will be using the Ready-Study-Go-Around-Europe! (RSGAE) project, which aims to produce online material for Vocational Education and Training, to demonstrate the role English plays within a European project, and its influence in the promotion of other European languages. It has been found that, on the one hand, ELF is crucial for interpersonal, administrative and academic communication within the project, and on the other hand, it foments the use of other EU languages for academic and professional purposes. Finally, it has been concluded that English in its role of lingua franca eases international communication and contributes to social, cultural and linguistic awareness in Europe.
\end{abstract}

\section{Introduction}

It is universally acknowledged that English is the vehicular language among citizens in Europe, so that, acquiring or learning it as a second (L2) or foreign language (FL) has become a need in our globalized society. Among the several uses speakers make of this language, the one that concerns the present case study is its role as lingua franca in European environments, especially in academic and professional settings.

There are numerous definitions of what English as a Lingua Franca (ELF) refers to. One of the most cited has been coined by Firth (1996), who defines ELF as a 'contact language between persons who share neither a common native tongue nor a common (national) culture, and for whom English is the chosen foreign language of communication'. This definition can be simplified to 'communication in English between speakers with different first languages’ (Seidlhofer, 2005). 
These definitions, along with many others, concur on pointing out the importance of English as the 'language of choice' among speakers who do not share linguacultural backgrounds (Jenkins, 2009), and who interact in different educational and working contexts. These interactions, together with students' mobility and internationalization, have had a great impact in the conception and use of other languages. One instance is the emergence of Languages for Specific Purposes (LSP), motivated by the practical need for standardization of terminology (De Rycker, Buyse, \& Vangehuchten, 2011) in order to achieve efficient international scientific and professional communication. Although its initiation has been dated in the early 60s with the fast development of industry, science and technology (Huckin, 2003), nowadays, LSP still refers to those linguistic manifestations that are specialized in form, content and use (De Rycker et al., 2011).

Although LSP and ELF have proved to have different objectives and motivations, it has been often debated that English represents a threat to other languages, including LSP. Such arguments suggest that in recent years there has been a 'shift' towards English, which has been arrogating space earlier occupied by other languages such as French or German (Phillipson, 2007), and that the dominance of English represents a threat to multilingualism, especially in the European Union (EU). According to a report of the European Commission, there are 23 different official languages in the EU that meet in a countless number of environments among which 'English is the most widely spoken foreign language in 19 of the 25 Member States where it is not an official language' (retrieved from http://ec.europa.eu/public_opinion/archives/ebs/ebs_386_en.pdf, most recently accessed May the 23, 2016).

Nevertheless, there are those who consider that the use of English in international situations provides a sense of inclusion (Modiano, 2009), as the interaction among speakers from different linguistic backgrounds and multicultural settings should not be restricted only to L2 contexts. This is to say that, according to this view, English could help to articulate meaning in people's L1 when communicating in specific contexts. Undoubtedly, the increasing interest for academic, social, economic and professional integration in Europe has awarded certain prestige to the knowledge of English as never before in history (Berns, 2009), however, its domain and scope in global communication has also been recognised to serve as a facilitator for European movement and integration (Hülmbauer, Böhringer, \& Seidlhofer, 2008).

Therefore, ELF is approached from an instrumental perspective that enables communication and does not displace local or national languages since English and local languages are used for different purposes (House, 2003) and in different settings. Furthermore, it is acknowledged that the role of English in foreign encounters, as well as its interpersonal use for social interaction among Europeans while travelling, at work or during exchange studies have contributed to mobility and the coexistence of languages. This matter has influenced the creation and intervention of mobility programmes within the EU. Probably the most important initiative for academic and working exchange in the last decades has been Erasmus+, which is the programme for Education, Training, Youth and Sport in the EU. This programme intends to offer opportunities within the continent in the fields of education, training, working experience and volunteering through small projects operating in education institutions and other organisations.

While it is true that a significant amount of studies have contributed to better understand and analyse the impact of these programmes and the role of English as a Lingua Franca (ELF) in personal, academic and professional settings (Crawford Camiciottoli, 2010; Marin, 2014; Dolga, Filipescu, Popescu-Mitroi, \& Mazilescu, 2015; Bryła, 2015; Endes, 2015), very few have characterized the projects and materials used to promote mobility and other European languages, as well as the conditions in which English is used to facilitate cross-cultural communication among students and professionals in the EU. Therefore, the case study in this paper will refer to the role of English as a Lingua Franca as a tool to promote multilingualism and facilitate communication among speakers of different European languages. In order to provide a pragmatic example, we will be using the Ready-Study-Go-Around-Europe! (RSGAE) 
Erasmus+ project, to demonstrate the role English plays within a European project, and its influence in the promotion of other European languages.

\section{The Study}

This study aimed to provide a practical example on how English can be used to promote other European languages for specific purposes. In order to do so, a case study was carried out in order to explore the way ELF operates within an Erasmus+ European project. The chosen project was RSGAE (Ready Study Go Around Europe!). In this stage we will learn about the project in depth: origin, objectives and the type of project it is. Afterwards, we depict the participants, divided into the learners and the team members of the project. Finally, the materials to be examined are presented. Special attention is given to the prototypes, as they served as models for the creation of the content packages within the project.

\subsection{The RSGAE Project}

The Ready Study Go Around Europe! Linguistic and Cultural Coaching in Initial Vocational Education, is an initiative that was originated in 2005 in Finland. Initially the materials were available in Estonian, French, German and Italian. For the period 2009-2011 of the project, three new languages were included: Spanish, Swedish and Turkish. The current RSGAE packages (2011-2014) are available in nine different European languages, including Hungarian and Polish.

The main objective of the project is to improve language and cross-cultural skills of people involved in vocational education and working life. This aim is pursued by producing linguacultural coaching materials in different European languages, and developing pedagogical alternatives in education, such as technologies, to support mobility. In order to do so, RSGAE's e-learning packages blend specific contents related to work and learning, with language and cultural situations that contribute to prepare the users for a work based or academic period abroad. Moreover, the packages are accessible through mobile phones, tablets at computer devices, which are expected to be used before and during real life working or learning situations in foreign settings.

\subsection{Type of European Project}

The RSGAE project makes part of the Leonardo da Vinci (LdV) sub-programme, which belongs to the Lifelong Learning Programme (LLP). This one, along with many other programmes operating in Europe (i.e., Erasmus, Comenius, Grundtvig), was integrated into the Erasmus+ programme in 2014. According to the European Commission website, the LLP ran between 2007 and 2013, and was designed to 'enable people at any stage of their life, to take part in stimulating learning experiences, as well as developing education and training across Europe' (retrieved from http://ec.europa.eu/education/tools/llp_en.htm, most recently accessed May the 26, 2016). Under this initiative, the LdV sub-programme is found. It aimed to provide grants to individuals and organisations in the EU that offer Vocational Education Training (VET) as well as skills, tools, methods and practice to perform in other countries. This focus well suited RSGAE's objectives and, therefore, it was allocated into this sub-programme.

\subsection{The Participants}

Based on the brief description of RSGAE, the type of project it is and the programme it belongs to, it is possible to broadly define the participants as people involved in education and training. This includes teachers, employers and training professionals involved in vocational education and training. 
For the purposes of this study, we divided the participants into: the learners (people who benefit from the materials); and the partners (teachers and professionals who create the materials). This was done in order to better understand and analyse their role in the project, as well as their specific use of language in the learning or creating process.

\subsubsection{The Learners}

RSGAE has targeted mainly people who are intending to gain experience and acquire the basic linguistic and cultural skills to perform in a particular area. These learners are ideally students going abroad for their work based learning period. They are expected to use the materials to learn the target language related to their profession, as well as to be familiarised with the working culture in the target country before they travel (retrieved from http://www.rsgo.eu/, most recently accessed May the 26, 2015). This profile includes students, employees, jobseekers, recent graduates and workers (among others) in the area of vocational or non-formal adult education.

Provided that the modules are conceived to be accessible online through internet connection in mobile phones, computers, laptops and tablets, it becomes indispensable that learners are habituated to the use of technology and mobile devices. This is because the packages (contents, links, audios, images and exercises) available online in the RSGAE platform, are intended to be usable for preparation outside and/or within work/study placement.

In so far as the language background, the users are expected to have a basic-intermediary level A2, according to the Common European Framework of Reference (CEFR) of linguistic competence in English. This is argued to be owed to the fact that English is used as the operative language within the platform so as to bridge over difficulties with the target EU language.

\subsubsection{The Partners}

The packages produced by RSGAE are considered to be suitable for teachers in vocational language teaching, employers guiding foreign trainees and work place instructors in their personnel training. However, in this analysis we only focused on the partners, who are the participants behind the creation, dissemination and evaluation of the packages and the project itself because they could constitute ideal examples on the use of ELF.

The working teams are composed of professionals in vocational education and language teachers who are experts in their own field. The network consists of 10 partners distributed in 8 EU countries: 2 from Finland (including the coordinator organisation), 2 from Hungary, and 1 from each of the following countries: Estonia, Sweden, Turkey, Ireland, Italy and Spain.

This multicultural approach is believed to provide a wide spectrum of expertise relevant all over Europe. Some of the members are specialists in fields such as elderly care, child care, higher education, vocational and adult education, tourism and hotel. These variety of professions is thought to provide a solid basis in the selection of topics and materials to be used in the packages.

\subsection{The Materials}

RSGAE's vocational content material is argued to be supported and supervised by experts in several fields, as well as by the Quality Manager of the project, who contributes to provide more reliable outcomes. The specific fields and areas to be included in the packages are discussed by the different members of each country's team so as to fit each target culture. A needs analysis by sectors is also claimed to be carried out. Below, the packages currently available in the project are listed, as well as some modules in the area, for the sake of illustrating some specific contents.

- Language and culture (included in all the packages): greetings, public transport, emergencies, shopping, getting around, working and living, celebrations. 
- Kitchen: staff, food and ingredients, service tools and equipment, basic skills, service situations, etc.

- Service: professional clothing, food service, mise en place, furniture, behaviour, wine service, etc.

- Bakery: machines and tools, professional clothing and attitude, professional vocabulary, hygiene, important food, etc.

- Hotel and tourism: staff, types of accommodation, special services, booking services and restaurants, shopping, sightseen, transport, etc.

- Vehicle: types of vehicles, the garage, body repair and painting, clothing, safety measures, workshop, equipment and tools, rent a car, service stations, etc.

- Child care: greeting children and parents, facilities, safety, activities, meeting child's needs, challenging situations, etc.

- Elderly care: personal care, medication, professional behaviour, ergonomics and prevention, staff, shifts at work, etc.

\subsubsection{The Prototypes}

The prototypes play a fundamental role in the creation of topics for the materials since they work as a model to be followed by all the partners in each of the participant countries. The prototypes are basically the first draft of a topic, which, as has been mentioned, is previously discussed with all the partners involved and evaluated by the Quality Manager of the project.

All the prototypes for each of the packages are written in English and its main function is to serve as a guideline for the different language versions. They are created by designated partners that are believed to be more related to the issued field. Each prototype, regardless of the creating partner/country's team, is built following a defined structure that allows the learner to be familiarized from the very beginning with the name of the module, the objectives and the general contents.

\section{Results}

In this section, findings arising from the analysis of the project are displayed. Initially, the use participants make of ELF is described. Afterwards, we point out the role of English in the creation of materials, specifically the prototypes. This is because, as aforementioned, prototypes constitute the 'backbone' of what is created in the project. The impact these issues have on Languages for Specific Purposes is also outlined.

Firstly, the learners who access the platform are expected to follow the users' instructions in English. Similarly, within the modules, they can resort to an English translation of the materials in order to solve doubts they might encounter in the target language. This was also true for self-correcting exercises, broadening information and surfing within the platform. This has been found to be a link between the learners' L1 and the target language.

As for the partners, it was found that English is the prime and chosen language for interpersonal communication, as well as for administrative and academic purposes. Channels such as emails, phone calls, videoconferences, online and live meetings, and platforms for document sharing take part in the interactions. In addition, English is used for coordinating reunions and personal meetings, discussing issues related to the project management, giving and receiving feedback, creating agreements, evaluating the processes, disseminating the project and elaborating documents (newsletters, posters, tutorials, reports, templates, samples, guidelines, reviews, etc.) among others. As for academic 
purposes, English is the vehicle in the discussions for to the selection of topics, contents and target sectors, as well as for the designation of tasks and distribution of materials' elaboration. These aspects are discussed in regular meetings held in one of the participant countries. The most recent one took place in Spain, specifically in the University of Alicante, between the 23rd and 24th April, 2015.

We now turn to the analysis of prototypes. It was found that each model starts with an objectives and contents section. The objectives are related to what is expected to be learnt within the module, and the contents are based on a list of agreed topics, which constitute the basic vocabulary, grammar and sociocultural skills to be acquired by the learner. Once the prototype is developed and finished, it is shared with the partners, and the team of each country transfers the model to their own language. In this process, the documents are modified to suit the target context. This includes glossaries, exercises, audios, texts, photographs, tests, grammar and additional information available within the final product: the packages. It is to note that the process does not involve direct translation, but an adaptation, accommodation and transference of information to each country's particular cultural, linguistic and working contexts. Although it is possible to observe differences between the initial prototype and the transferred model to each EU partner, the foundations of the prototype remain unaltered. This has been considered as an aspect that demonstrates how LSP can be promoted, as each partner access information through English, but then use the specific EU language and terminology to transfer and adapt contents to their own local-national culture.

Finally, once the contents and materials of the module have been adapted to the target language of each country, the new products are now translated to English. Thus, the transferred materials are now translated to a common language in order to share information within the working community. Therefore, the linguistic features and cultural aspects of each country can be shared and accessible to the rest of participants.

\section{Conclusions}

As previously stated, this case study has been conducted in order to demonstrate how English as a Lingua Franca can be used to promote multilingualism. To this end, we intended to exemplify the way ELF facilitates communication among speakers of different European languages and fosters LSP through the analysis of the RSGAE project.

First of all, it is possible to conclude that the variety of processes of intracultural communication in English that take place among partners with different L1, constitute authentic instances of ELF encounters. Besides that, the creation of prototypes in English and the transfer of materials to Estonian, Finnish, Hungarian, Italian, Swedish, Turkish, Polish and Spanish, have contributed to foster the mentioned European cultures and languages. Thus, we can suggests that English can be used not only as an intermediator between the European language studied and the learner's mother tongue, but as a promoter of other EU languages.

Therefore, we can assert that within RSGAE, English is, in fact, a contact or vehicular language among speakers from different cultural and linguistic backgrounds. Hence, although it has been considered by many as a threat to national languages, we hope that through this modest study we have contributed to the notion that English enables communication in different contexts, and promotes social, cultural and linguistic awareness in Europe.

Additionally, the study allowed us to examine the way certain Vocational Education and Training projects operate in the continent, as well as the policies behind their foundation and the benefits they could represent to both students and teachers. Therefore, considering the relevance ELF has been claimed to have, along with the importance projects such as RSGAE have in EU mobility, it is possible to affirm that English enhances not only communication, but also vocational education and professional development. 
In so far as the promotion of LSP is concerned, we have provided descriptions on the use of English as a Lingua Franca for interpersonal, administrative and academic communication within the participants in the project, which provided evidence on the importance English has for international interactions. Moreover, we pointed out its utility to foster other languages for specific purposes in Europe, specifically the ones that participate in the project. These considerations allow us to become more aware on the importance of LSP in academic and professional settings, due to its demonstrated value as a tool for linguistic and sociocultural integration.

Finally, this work has constituted a small seed in the field of academic research regarding the use of English within projects and mobility programmes in Europe, principally those in which languages are used for specific academic and professional purposes.

\section{References}

Berns, M. (2009). English as Lingua Franca and English in Europe. World Englishes, 28(2), 192199. http://doi.org/10.1002/9781405198431.wbeal0375

Bryła, P. (2015). The Impact of International Student Mobility on Subsequent Employment and Professional Career: A Large-scale Survey among Polish Former Erasmus Students. Procedia - Social and Behavioral Sciences, 176, 633-641. http://doi.org/10.1016/j.sbspro.2015.01.521

Crawford Camiciottoli, B. (2010). Meeting the challenges of European student mobility: Preparing Italian Erasmus students for business lectures in English. English for Specific Purposes, 29(4), 268280. http://doi.org/10.1016/j.esp.2010.01.001

De Rycker, A., Buyse, K., \& Vangehuchten, L. (2011). LSP research today: a general approach for specific purposes? ITL International Journal of Applied Linguistics. Katholieke Universiteit Leuven. Retrieved

from http://dialnet.unirioja.es/servlet/articulo?codigo=4130789\&info=resumen\&idioma=ENG

Dolga, L., Filipescu, H., Popescu-Mitroi, M. M., \& Mazilescu, C. A. (2015). Erasmus Mobility Impact on Professional Training and Personal Development of Students Beneficiaries. Procedia - Social and Behavioral Sciences, 191, 1006-1013. http://doi.org/10.1016/j.sbspro.2015.04.235

Endes, Y. Z. (2015). Overseas Education Process of Outgoing Students within the Erasmus Exchange Programme. Procedia - Social and Behavioral Sciences, 174, 1408-1414. http://doi.org/10.1016/j.sbspro.2015.01.768

Firth, A. (1996). The discursive accomplishment of normality: On "lingua franca" English and conversation analysis. Journal of Pragmatics, 26(2), 237-259. http://doi.org/10.1016/03782166(96)00014-8

House, J. (2003). English as a lingua franca: A threat to multilingualism? Journal of Sociolinguistics, 7(4), 556-578. http://doi.org/10.1111/j.1467-9841.2003.00242.x

Huckin, T. N. (2003). Specificity in LSP. Ibérica: Revista de La Asociación Europea de Lenguas Para Fines Específicos ( AELFE ). Asociación Europea de Lenguas para Fines Específicos (AELFE). Retrieved from http://dialnet.unirioja.es/servlet/articulo?codigo=5000517\&info=resumen\&idioma=SPA

Hülmbauer, C., Böhringer, H., \& Seidlhofer, B. (2008). Introducing English as a lingua franca (ELF): Precursor and Partner in Intercultural Communication. Enseigner Apprendre Utiliser Le Francais Langue Internationale En Europe Aujourdhui Pour Une Perspective Comparatiste Synergies Europe 309, 3, 25-36. http://doi.org/10.1515/IPRG.2009.008

Jenkins, J. (2009). English as a lingua franca: Interpretations and attitudes. World Englishes, 28(2), 200-207. http://doi.org/10.1111/j.1467-971X.2009.01582.x

Marin, E. (2014). The Mobility of Romanian Students in Europe. Procedia - Social and Behavioral Sciences, 116, 4884-4888. http://doi.org/10.1016/j.sbspro.2014.01.1043 
Modiano, M. (2009). Inclusive/exclusive? English as a lingua franca in the European Union. World Englishes, 28(2), 208-223. http://doi.org/10.1111/j.1467-971X.2009.01584.X

Phillipson, R. (2007). English, no longer a foreign language in Europe? In J. Cummins \& C. Davison (Eds.), International Handbook of English Language Teaching (pp. 123 - 136). Boston, MA: Springer US. http://doi.org/10.1007/978-0-387-46301-8

Seidlhofer, B. (2005). English as a lingua franca. ELT Journal, 59(4), 339-341. http://doi.org/10.1093/elt/cci064 